\title{
Cuff-Less and Continuous Blood Pressure Monitoring: A Methodological Review
}

\author{
Manuja Sharma ${ }^{1}$, Karinne Barbosa ${ }^{1}$, Victor Ho ${ }^{1}$, Devon Griggs ${ }^{1}$, Tadesse Ghirmai ${ }^{1}$, \\ Sandeep K. Krishnan ${ }^{2}$, Tzung K. Hsiai ${ }^{3}$, Jung-Chih Chiao ${ }^{4}$ and Hung Cao ${ }^{1, *}$ \\ 1 Division of Engineering and Mathematics, School of Science, Technology, Engineering and Mathematics, \\ University of Washington, Bothell, WA 98011, USA; manuja21@gmail.com (M.S.); \\ karinnejcbarbosa@gmail.com (K.B.); vhau422@gmail.com (V.H.); devongriggs@outlook.com (D.G.); \\ tadg@uw.edu (T.G.) \\ 2 Division of Interventional Cardiology, Department of Medicine, School of Medicine, \\ University of Washington, Seattle, WA 98195, USA; sdizzle@cardiology.washington.edu \\ 3 Division of Cardiology, David Geffen School of Medicine, University of California, Los Angeles, CA 90095, \\ USA; THsiai@mednet.ucla.edu \\ 4 Department of Electrical Engineering, University of Texas Arlington, Arlington, TX 76019, USA; \\ jcchiao@uta.edu \\ * Correspondence: hungcao@uw.edu; Tel.: +1-425-352-5194
}

Academic Editors: Alessandro Tognetti and Nicola Carbonaro

Received: 5 March 2017; Accepted: 5 May 2017; Published: 9 May 2017

\begin{abstract}
Blood pressure (BP) is one of the most important monitoring parameters in clinical medicine. For years, the cuff-based sphygmomanometer and the arterial invasive line have been the gold standards for care professionals to assess BP. During the past few decades, the wide spread of the oscillometry-based BP arm or wrist cuffs have made home-based BP assessment more convenient and accessible. However, the discontinuous nature, the inability to interface with mobile applications, the relative inaccuracy with movement, and the need for calibration have rendered those BP oscillometry devices inadequate for next-generation healthcare infrastructure where integration and continuous data acquisition and communication are required. Recently, the indirect approach to obtain BP values has been intensively investigated, where BP is mathematically derived through the "Time Delay" in propagation of pressure waves in the vascular system. This holds promise for the realization of cuffless and continuous BP monitoring systems, for both patients and healthy populations in both inpatient and outpatient settings. This review highlights recent efforts in developing these next-generation blood pressure monitoring devices and compares various mathematical models. The unmet challenges and further developments that are crucial to develop "Time Delay"-based BP devices are also discussed.
\end{abstract}

Keywords: blood pressure; pulse transit time; pulse arrival time; electrocardiogram (ECG); photoplethysmography (PPG)

\section{Introduction}

Cardiovascular disease (CVD) plagues our aging society as the leading cause of morbidity and mortality in developed countries [1,2]. High blood pressure (BP) or hypertension (HTN) is a common condition leading to CVD. HTN is determined by increased pressure in the arteries that can lead to stress on the heart, also known as hypertensive heart disease. About 67 million American adults (31\%) are affected by HTN, while only $47 \%$ of patients maintain normal BP control [3]. Further, HTN has also been found associated with other health issues in various groups of populations, such as the elderly and pregnant women, to name a few $[4,5]$. 
Conventionally, non-invasive BP has been measured using a sphygmomanometer based on the design proposed by Samuel Siegfried Karl Ritter von Basch in 1881 [6]. Riva Rocci further improved the design by developing a branchial cuff sphygmomanometer in 1896 [7]. The detection of Kortokoff sound (K-sound) in 1905 enabled complete non-invasive BP measurement [8]. The pressure indicated by the manometer at the first K-sound is noted as the systolic BP (SBP) and the silent fifth sound indicates the diastolic BP (DBP) (Figure 1a) [8-10]. In the past few decades, oscillometry-based $\mathrm{BP}$ tools have become popular, providing ease of operation. They do not require a caregiver or experienced personnel to operate and hence can be used to monitor BP in the home setting. These devices have a cuff wrapping around the arm or leg to detect the oscillations during cuff-deflation using a built-in pressure sensor. Mean arterial pressure (MAP) is estimated using the amplitude variations of the recorded oscillations which are used to algorithmically obtain SBP and DBP [11,12] (Figure 1b). However, a recent study by Leung et al. indicated over three in ten home BP monitoring cuffs were inaccurate [13]. Further, cuff-based devices are cumbersome and cannot perform continuous measurements. Thus it is difficult to be integrated with wearable technologies, which continue to gain popularity in commercial sectors and clinical practice. Ambulatory blood pressure monitoring (ABPM) has been used to diagnose HTN in the outpatient setting. Although, ABPM is superior to the isolated, sporadic monitoring of patient's BP generally affected by "white coat" HTN (or "white coat syndrome", referring to a phenomenon in which people only exhibit HTN in a clinical setting), the current ABPM in use is a bulky device that is not portable or practical for daily or long-term uses [14].

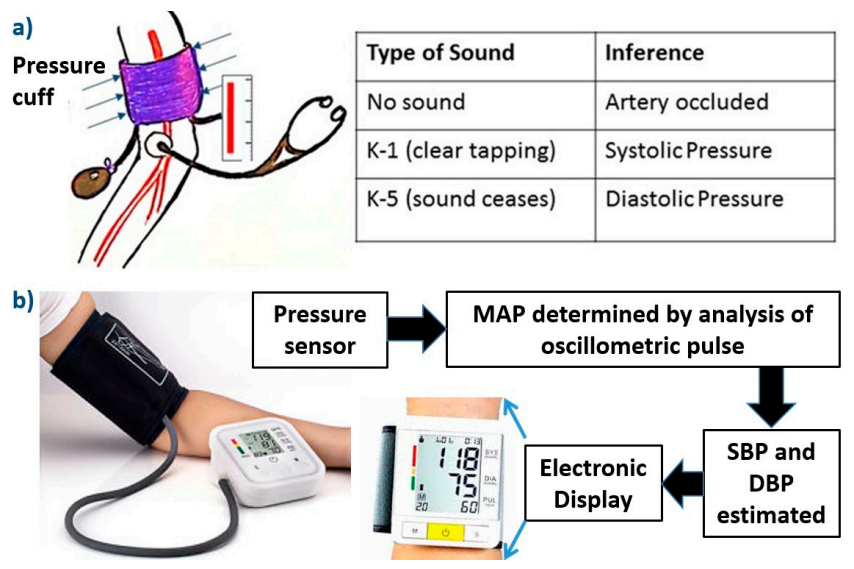

Figure 1. Conventional blood pressure (BP) measurement. (a) Sphygmomanometer; and (b) Oscillometrybased BP measurement.

Finapres (Finapres Medical Systems, the Netherlands), a device that measures finger arterial pressure using a finger cuff and infrared plethysmograph, has been gaining in popularity $[15,16]$. Though having a smaller cuff, the processing device still makes it inadequate to provide continuous data for daily use. Additionally, it is also motion-sensitive and cannot be reliably used to measure BP during normal activities.

In the past few years, several research groups have developed cuff-less BP monitoring wearable devices, holding promise to allow patients to continuously monitor BP without interruption to their daily activities [17-21]. The underlying principle of these devices is based on the relation of the time it takes for a volume of blood (in the form of a pulse) to travel from the heart to a peripheral organ, which could be in the form of pulse transit time (PTT) or pulse arrival time (PAT) [22-24]. Algorithms and mathematical models have been proposed and developed to optimize the regression process and calibration of the traveling/delay time ("Time Delay") and BP [25-27]. The "Time Delay" is usually obtained using a cardiac electrical signal, i.e., electrocardiogram (ECG), recording device and a pulse oximeter at a peripheral organ, i.e., photoplethysmography (PPG) $[28,29]$. However, existing systems are not continuous as most of the ECG acquisition approaches require a cross-body configuration, 
asking the user to touch an open electrode on the wearable device; hence continuous measurements of BP have not been achieved $[17,30]$. Though these devices overcome issues of other non-invasive tools, several critical issues still remained. First, some devices anchor to the body, which some users may find irritating [31]. Second, this approach requires frequent calibration to map the "Time Delay" and BP to maintain accuracy and all existing fitting models appear to be dependent of objects and temporal trials, as well as motional activities $[32,33]$. Third, time synchronization between different bio-signals to obtain "Time Delay" is crucial as the system's input parameter is in milliseconds. Fourth, the dependence of BP on other factors, such as vasomotor tones, neural control and heart rate, requires additional parameters to be included along with PTT/PAT in the mathematical model to adequately estimate BP [34,35]. Lastly, the accuracy measured via the regression coefficient $\left(R^{2}\right)$ is low, with significant value variations even in the same subject at the same activity level [36,37], suggesting a more-sophisticated mathematical model may be a solution to enable BP monitoring devices with higher reliability and precision, which can later be accepted as practical medical-grade tools.

This methodological review provides an overview of the physical relationship between blood pressure and the "Time Delay" of cardiac signals in a human's cardiovascular system, as well as the existing mathematical models to derive BP from "Time Delay" measurements. Thorough comparisons among methods are achieved using our recording data [38] and those obtained from the Physionet's Multi-parameter Intelligent Monitoring in Intensive Care (MIMIC) II (Version 3, accessed in December 2016) online waveform database [39]. Collectively, challenges and important issues of wearable, home-based, cuffless and continuous BP monitoring are discussed in detail.

\section{Cardiovascular System and the Electrical-Mechanical Coupling of the Heart}

\subsection{Electro-Mechanical Cardiac Signals}

The heart's electrical system, also known as the cardiac conduction system, consists of three main components: sinoatrial (SA) node, atrioventricular (AV) node and His-Purkinje system. It is usually recorded as the ECG signal [40] (Figure 2a). The SA node, located in the upper portion of the right atrium, is the heart's intrinsic pacemaker that initiates electrical signal, indicated as the P-wave of the patient's ECG. Generated electrical signals result in atrial contraction and help push blood through the atrioventricular valves into both ventricles. The electrical impulse then activates the AV node, a relay station, situated above the ventricles. It facilitates right and left atriums to empty their blood contents into the two ventricles (corresponding to PR intervals of ECG). Once released, the electrical signal moves along the electrical highway (the "bundle of His"-transmits impulses from the atrioventricular node to the ventricles of the heart) which later divides into Purkinje fibers connected to cells in the walls of the left and right ventricles. This causes the electrically stimulated ventricles to contract and pump oxygenated blood into the arteries. This entire phase represents the QRS complex of an ECG. Later stages of the ECG signal represent the repolarization phase of the ventricles ( $T$ waves) $[41,42]$.
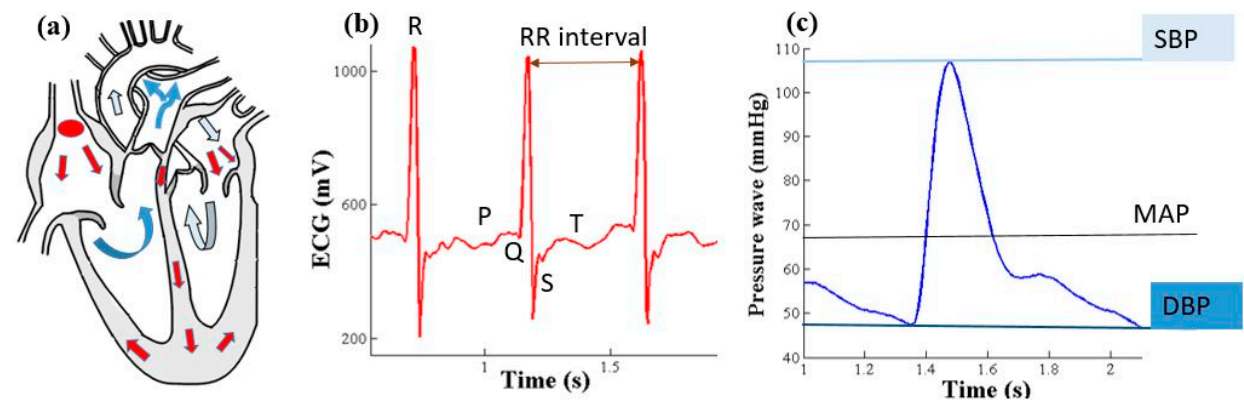

Figure 2. (a) Electro-mechanical signal generated in human heart; (b) electrocardiogram (ECG) signal; and (c) pressure wave. 
Electrical-mechanical coupling of the heart results in blood ejection into the arterial tree, affecting the blood velocity and generating a systemic pressure wave traveling from the central to peripheral arteries. The pressure wave causes dilation of the arterial walls on its path and moves faster than the blood flow $[43,44]$. It varies periodically between two extreme points, maximum and minimum, referring to $\mathrm{SBP}$ and $\mathrm{DBP}$, as the pressure in the artery due to ventricular contraction and the pressure in the artery during each beat, respectively. The mean value of the pressure wave, termed MAP (Figure 2c), is estimated as:

$$
\mathrm{MAP}=\mathrm{DBP}+\frac{1}{3}(\mathrm{SBP}-\mathrm{DBP})
$$

This pressure waveform can be directly obtained using a pulse sensor on the peripheral arteries or indirectly measured through a pulse oximeter, namely a PPG sensor. Since the pressure wave causes the blood volume to change at the peripheral site, it can be detected by measuring the variation of the oxygen content of the blood caused by influx of oxygenated blood on the arrival of the pressure wave, indicated as the first peak on the PPG waveform [45]. Many other vital parameters can be estimated using PPG as discussed in section C.

\subsection{Relationship between BP, Pressure Wave Velocity (PWV) and Time Period}

The central arteries push blood to narrow distal arteries by expanding during systole and contracting during diastole [46]. This expansion and contraction results in changes of the elastic modulus $(E)$ of the vessels and is related to the fluid pressure $P$ as below:

$$
E=E_{o} e^{\alpha P}
$$

In Equation (2), $\alpha$ is a vessel parameter (Euler number) and $E_{0}$ is the Young's modulus for zero arterial pressure. These two are subject-specific parameters [47-49]. Equation (2) estimates the central arterial pressure if $\alpha$ and $E_{o}$ are updated by accounting for the age and health impacts on the elasticity due to the change in the wall composition. Arterial walls are composed of endothelium, elastin, collagen, and smooth muscle (SM) cells in varying quantities at central and peripheral sites [50,51]. Different compositions as well as gradual replacement of elastin with collagen changes the elasticity of these arteries, resulting in changes in central and peripheral BP [52,53]. A detailed analysis of elastic and viscous properties of the arterial tree can be found in the review [54] which describes how the central arterial elasticity is determined by the BP and also how the peripheral elasticity is affected by both BP and SM contraction [55]. Hence, the peripheral elasticity cannot be accurately predicted by Equation (2).

The elasticity of arteries determines the propagation speed, the pressure wave velocity (PWV); a relationship can be obtained between them using arterial wave propagation models. Assuming the artery to be an elastic tube with a thickness $h$, diameter $d$ and blood density $\rho$, we have the Moens-Kortweg equation as follows [56]:

$$
\mathrm{PWV}=\sqrt{\frac{h E}{\rho d}}
$$

Combining Equations (2) and (3), we obtain the Bramwell-Hills and Moens-Kortweg's equation, representing the relationship between P and PWV and hence the "Time Delay" for an artery with a length of $L$ [44]:

$$
\mathrm{PWV}=\frac{L}{\text { Time Delay }}=\sqrt{\frac{h E_{o} e^{\alpha P}}{\rho d}}
$$

This equation indicates that the rise in pressure, with other parameters constant, will result in an increase in PWV and inversely affects the "Time Delay". 


\subsection{Determination of the "Time Delay"}

\subsubsection{Pulse Transit Time (PTT)}

PTT refers to the time taken by a pressure wave to travel between two arterial sites and is inversely related to BP (Figure 3a). PTT can be measured using different techniques like Ultrasound Doppler and arterial tonometry [57-59]. The latter can be obtained by observing two distant PPG waves (Figure 3c). Ears, toes and fingers are common sites used for measurement [60]. PTT $_{\mathrm{f}}$ measured from the foot of one PPG to that of another has been demonstrated to have a strong correlation to invasive DBP [61], but a study on 44 normotensive male subjects concluded otherwise [62]. The peaks of PPG that theoretically represent SBP have been found to be unreliable indicators of SBP. These peaks are distorted by reflection of pressure waves from the terminal arteries. Chen et al. proposed a novel method based on experimental data to use the mean of $\mathrm{PTT}_{\mathrm{fp}}$ (time delay between falling edge of

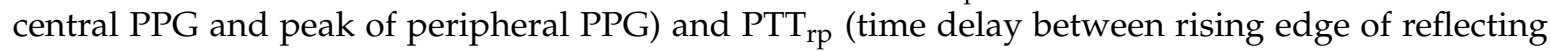
central PPG and peak of peripheral PPG) to obtain PTT for SBP (Figure 3c) [63]. Other studies have indicated that posture, ambient temperature, and relaxation affect PPG, raising a question on the development of an accurate PTT device [64].

(a)

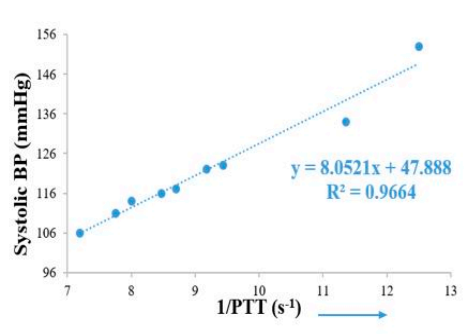

(b)

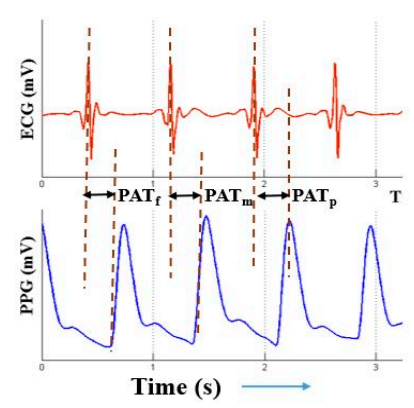

(c)

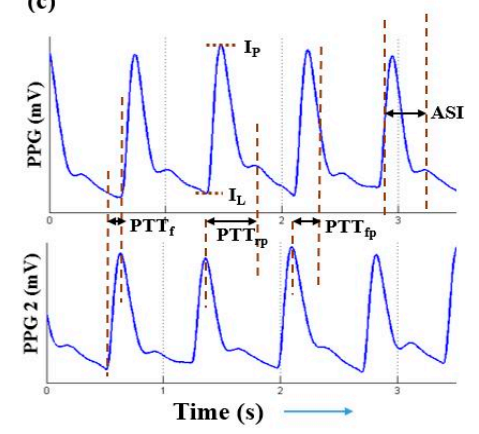

Figure 3. (a) Inverse relationship between pulse transit time (PTT) and systolic blood pressure (SBP) from our data; (b) Pulse arrival time (PAT) using different characteristic points of the photoplethysmography (PPG) waveform; (c) Different types of PTT and other PPG parameters.

\subsubsection{Pulse Arrival Time (PAT)}

Another popular and convenient method to measure the "Time Delay" is based on the time difference between the R-peak of ECG and a characteristic point of PPG peak (Figure 3b). Different time stamps on the PPG waveform, such as foot [65-67], peak [67-69] and mid-point of the rising edge $[29,70,71]$, have been considered to estimate the "Time Delay" (Figure 3b). Though some studies reported this delay as PTT, it is more accurately known as Pulse Arrival Time (PAT) as in addition to the PTT of the pressure wave, it includes the Pre-ejection Period (PEP) delay. PEP is the time needed to convert the electrical signal into a mechanical pumping force and isovolumetric contraction to open the aortic valves $[43,72]$ :

$$
\mathrm{PAT}=\mathrm{PTT}+\mathrm{PEP}
$$

PEP is a delay that changes with stress, physical activity, age and emotion [48]. A study has attempted to estimate PEP as a percentage of the RR interval as, with a low heart rate, PEP becomes more significant [73]. They approximated PEP as 7\% of the RR interval and concluded that it should be subtracted out to obtain PTT. The impact of PEP on the overall PTT decreases with distance from the heart. Thus for short PTTs, especially those extracted from ear PPQ, it is needed to accommodate for this electro-mechanical delay, or PEP. Nevertheless, the effect of including PEP in BP estimation is still under investigation. Some have reported the relationship of PEP with PAT [74-76], while others find it a weak surrogate $[77,78]$. There were studies indicating that all SBP, DBP and MAP are less correlated 
to PAT as compared to PTT [79], while others stating PAT is a better indicator of SBP $[80,81]$ as it is dependent on both ventricular contraction and vascular function.

\section{Mathematical Models}

Mathematical relationships between BP and the "Time Delay" or PTT/PAT reported in the literature are derivatives of the physical model previously discussed and summarized in Table 1. We will discuss several models below. 
Table 1. Summary of mathematical models to calculate BP from PTT/PAT.

\begin{tabular}{|c|c|c|c|c|c|c|}
\hline \multirow{2}{*}{ Algorithm } & \multirow{2}{*}{ Time Delay } & \multirow{2}{*}{ Calibration Technique } & \multicolumn{3}{|c|}{ Results } & \multirow{2}{*}{ Refs } \\
\hline & & & SBP & DBP & MAP & \\
\hline \multirow{3}{*}{$\mathrm{aln}($ Time Delay $)+\mathrm{b}$} & $\mathrm{PTT}_{\mathrm{f}}$ & \multirow{3}{*}{ Subject specific } & $-0.22 \pm 0.46^{2}$ & \multirow{2}{*}{-} & \multirow{2}{*}{-} & \multirow{3}{*}{ [82] } \\
\hline & $\mathrm{PAT}_{\mathrm{f}}$ & & $-0.85 \pm 0.09^{2}$ & & & \\
\hline & $\mathrm{PTT}_{\mathrm{f}}$ & & & $0.9^{3}$ & & \\
\hline$\frac{\mathrm{A}}{\mathrm{PAT}^{2}}+\mathrm{B}$ & $\mathrm{PAT}_{\mathrm{p}}$ & $\begin{array}{l}\text { A: Dependent on Height } \\
\text { B: Subject specific }\end{array}$ & $0.0790 \pm 11.32^{1}$ & - & - & [73] \\
\hline \multirow{11}{*}{$\mathrm{aPAT}+\mathrm{b}$} & $\mathrm{PAT}_{\mathrm{f}}$ & Subject specific & $0.99-0.90^{2}$ & - & - & [65] \\
\hline & \multirow{2}{*}{$\mathrm{PAT}_{\mathrm{p}}$} & \multirow{2}{*}{ Subject specific } & $-0.92^{2}$ & $-0.38^{2}$ & \multirow{2}{*}{-} & \multirow{2}{*}{ [83] } \\
\hline & & & RT: $-0.87^{2, *}$ & RT: $-0.30^{2, *}$ & & \\
\hline & $\mathrm{PAT}_{\mathrm{m}}$ & Subject specific & $0.701^{3}$ & $0.401^{3}$ & - & [84] \\
\hline & $\mathrm{PAT}_{\mathrm{p}}$ & Subject specific & $0.95-0.87^{3}$ & $0.01-0.73^{3}$ & - & [85] \\
\hline & $\mathrm{PAT}_{\mathrm{p}}$ & \multirow{3}{*}{ Subject specific } & $-0.71^{2}$ & $-0.69^{2}$ & \multirow{3}{*}{-} & \multirow{3}{*}{ [25] } \\
\hline & $\mathrm{PAT}_{\mathrm{m}}$ & & $-0.32^{2}$ & $-0.22^{2}$ & & \\
\hline & $\mathrm{PAT}_{\mathrm{f}}$ & & $-0.09^{2}$ & $-0.02^{2}$ & & \\
\hline & $\mathrm{PAT}_{\mathrm{p}}$ & \multirow{3}{*}{ Subject specific } & & & $0.32^{2}$ & \multirow{3}{*}[28]{} \\
\hline & $\mathrm{PAT}_{\mathrm{m}}$ & & & & $0.27^{2}$ & \\
\hline & $\mathrm{PAT}_{\mathrm{f}}$ & & & & $0.45^{2}$ & \\
\hline \multirow{2}{*}{$\frac{a}{\mathrm{PAT}}+b$} & $\mathrm{PAT}_{\mathrm{p}}$ & \multirow{2}{*}{ Subject specific } & $0.95^{3}$ & $0.26^{3}$ & & [69] \\
\hline & $\mathrm{PAT}_{\mathrm{m}}$ & & $0.89^{3}$ & $0.78^{3}$ & & [86] \\
\hline$\frac{a}{\text { PAT }}+b+c * V P A T+d *\left(P A T V-\right.$ PATV $\left._{0}\right)$ & $\mathrm{PAT}_{\mathrm{p}}$ & & $0.96^{3}$ & $0.70^{3}$ & - & [69] \\
\hline$a+\left(\frac{b}{\text { PAT }-c}\right)^{2}$ & $\mathrm{PAT}_{\mathrm{p}}$ & Subject specific & $0.97 \pm 0.87^{3}$ & $0.54 \pm 0.05^{3}$ & - & [85] \\
\hline \multirow{2}{*}{$\frac{(P W V-a)}{b}$} & $\mathrm{PAT}_{\mathrm{f}}$ & \multirow{2}{*}{ Subject specific } & $0.93^{2}$ & \multirow{2}{*}{-} & $0.83^{2}$ & \multirow{2}{*}[87]{} \\
\hline & $\mathrm{PAT}_{\mathrm{f}}$ & & $0.94^{2}$ & & $0.86^{2}$ & \\
\hline \multirow{2}{*}{$\mathrm{aPAT}+\mathrm{bHR}+\mathrm{c}$} & $\mathrm{PAT}_{\mathrm{m}}$ & $\begin{array}{l}\text { Subject specific, Maximum } \\
\text { Likelihood }\end{array}$ & $0.978^{3}$ & $0.974^{3}$ & - & \multirow{2}{*}{ [88] } \\
\hline & $\mathrm{PAT}_{\mathrm{m}}$ & $\begin{array}{l}\text { Subject specific, Adaptive } \\
\text { Kalman filter }\end{array}$ & $0.976^{3}$ & $0.989^{3}$ & - & \\
\hline $\mathrm{a}+\mathrm{bPAT}+\mathrm{cHR}+\mathrm{dTDB}$ & $\mathrm{PAT}_{\mathrm{m}}$ & Subject specific & $0.85^{3}$ & $0.74^{3}$ & - & [84] \\
\hline
\end{tabular}


Table 1. Cont.

\begin{tabular}{|c|c|c|c|c|c|c|}
\hline \multirow{2}{*}{ Algorithm } & \multirow{2}{*}{ Time Delay } & \multirow{2}{*}{ Calibration Technique } & \multicolumn{3}{|c|}{ Results } & \multirow{2}{*}{ Refs } \\
\hline & & & SBP & DBP & MAP & \\
\hline \multirow{2}{*}{$\begin{array}{c}\mathrm{BP}_{\mathrm{ij}}=\mathrm{b}_{\mathrm{ij}} \mathrm{e}^{-\left(\frac{K_{\mathrm{ij}}}{P \mathrm{PW}_{\mathrm{ij}}}\right)} \\
\mathrm{i}=1,2, \ldots, \mathrm{m}(\text { age }) \text { and } \mathrm{j}=\text { Male } / \text { Female }\end{array}$} & $\mathrm{PTT}_{\mathrm{f}}$ & \multirow{2}{*}{$\begin{array}{l}b_{i j} \text { and } K_{i j} \text { are calculated for a } \\
\text { demographically similar group. }\end{array}$} & - & $-1.49 \pm 6.51^{1}$ & \multirow{2}{*}{ - } & \multirow{2}{*}[61,63]{} \\
\hline & $\mathrm{PTT}_{\mathrm{fp}}+\mathrm{PTT}_{\mathrm{rp}}$ & & $2.16 \pm 6.23^{1}$ & - & & \\
\hline $\begin{array}{c}\mathrm{DBP}=\frac{\mathrm{SBP}_{0}}{3}+\frac{2 \mathrm{DBP}_{0}}{3}+\operatorname{aln}\left(\frac{\mathrm{PAT}_{\mathrm{W}}}{\mathrm{PAT}_{\mathrm{W}}}\right)-\frac{\left(\mathrm{SBP}_{0}-\mathrm{DBP}_{0}\right)}{3}\left(\frac{\mathrm{PAT}_{\mathrm{W}}}{\mathrm{PAT}_{\mathrm{W}}}\right)^{2} \\
\mathrm{SBP}=\mathrm{DBP}_{0}+\left(\mathrm{SBP}_{0}-\mathrm{DBP}_{0}\right)\left(\frac{\mathrm{PAT}_{\mathrm{W}}}{\mathrm{PAT}_{\mathrm{W}}}\right)^{2}\end{array}$ & $\mathrm{PAT}_{\mathrm{m}}$ & Subject specific & $0.6 \pm 9.8^{1}$ & $0.9 \pm 5.6^{1}$ & - & [30] \\
\hline $\mathrm{BP}=\mathrm{a} * \mathrm{PWV} * \mathrm{e}^{\mathrm{b} * \mathrm{PMV}}+\mathrm{cPWV}^{\mathrm{d}}-\left(\mathrm{BP}_{\mathrm{PTT}, \mathrm{cal}}-\mathrm{BP}_{\mathrm{PTT}}\right)$ & $\mathrm{PAT}_{\mathrm{m}}$ & Universal & $0.83^{2}$ & - & - & [89] \\
\hline $\begin{array}{c}\mathrm{DBP}=\mathrm{DBP}_{0} \frac{\mathrm{PIR}_{0}}{\mathrm{PIR}^{2}} \\
\mathrm{SBP}=\mathrm{DBP}_{0} \frac{\mathrm{PIR}_{0}}{\mathrm{PIR}}+\mathrm{PP}_{0}\left(\frac{\mathrm{PAT}_{0}}{\mathrm{PAT}}\right)^{2}\end{array}$ & $\mathrm{PAT}_{\mathrm{m}}$ & Subject specific & $0.91^{2}$ & $0.88^{2}$ & $0.89^{2}$ & [90] \\
\hline
\end{tabular}

${ }^{1}$ Mean $\pm S D ;{ }^{2}$ r: Correlation Coefficient; ${ }^{3} \mathrm{R}^{2}$ : Coefficient of Determination; * RT: Repeatability Test. 


\subsection{Logarithmic Model}

The Bramwell-Hills and Moens-Kortweg's equation gives a logarithmic relationship between BP and the "Time Delay". Assuming the density of blood $(\rho)$, the diameter of artery $(d)$, the thickness of the artery $(h)$, the distance at which the "Time Delay" is obtained $(L)$, and the elasticity $\left(E_{o}\right)$ are constant for a subject, we can have relationship of BP and the "Time Delay" represented as:

$$
\mathrm{BP}=a \ln (\text { Time Delay })+b
$$

Here, $a$ and $b$ are subject-specific constants and they can be obtained through a regression analysis between the reference BP and the corresponding "Time Delay" [82]. Proença et al. estimated SBP with this mathematical model Equation (6) using both PTT and PAT [82]. They determined PTT from two PPG sensors placed at the earlobe and at a finger, and PAT with PEP adjustment using the impedance cardiogram. However, they found inconsistent results with both of them. Poon et al. established a relationship between MBP and the "Time Delay" using Equation (6) and obtained SBP and DBP using Equation (1) and a factor that accounts for the change in elasticity due to pressure wave variations [30]. Their results agreed with the AAMI (American Association for the Advancement of Medical Instrumentation) standard of a BP device with the mean difference of less than $5 \mathrm{mmHg}$ and standard deviation within $8 \mathrm{mmHg}$ [91]. Hence, this method has become popular to indirectly obtain BP via the "Time Delay".

The logarithmic model Equation (6) approaches negative infinity as "Time Delay" tends to zero, making it difficult to use this relationship to represent small BP [61].

\subsection{Proportional (Linear) Model}

Assuming there is a negligible change in the arterial thickness and diameter with pressure variations, BP and the "Time Delay" can be linearly related by differentiating the Moens-Kortweg's Equation (3) with respect to time Equation (6) [65]. Chen et al. obtained a high correlation factor between the measured SBP and the calculated SBP using $\mathrm{PAT}_{\mathrm{f}}$ and thus they established a calibration model that varies according to fluctuation in PAT.

$$
\mathrm{BP}=a(\text { Time Delay })+b
$$

Using Equation (7), a study attempted to estimate SBP and DBP for 14 normotensive subjects and then carried out a repeatability test after six months to verify whether the model still holds or not [83]. In their study, PAT $_{\mathrm{p}}$ was obtained for each subject before, during and after exercise. The repeatability test showed that although the range of $\mathrm{a}$ and $\mathrm{b}$ were similar to the values obtained previously, errors on calculating BP using the "six-month old calibrated algorithm" were significant. The authors also reported that there was less correlation between DBP and PAT which could be due to the fact that $\mathrm{PAT}_{\mathrm{p}}$, instead of $\mathrm{PAT}_{\mathrm{f}}$, was used to estimate DBP. Choi et al. used the same algorithm and investigated the use of different characteristic points of PPG (Figure 3b) and calibration intervals to achieve BP [25]. In their work, they concluded that $\mathrm{PAT}_{\mathrm{p}}$ measurements and one hour calibration intervals provided better estimates of BP within error limits. Further, it was claimed that the algorithm was adopted not only for its better performance, but also for its robustness against motion artifacts that exist in non-invasive waveforms.

Several other studies have integrated the linear BP algorithm (7) with other influencing factors, such as heart rate (HR) and arterial stiffness index (ASI) (Figure 3c), that would affect BP $[48,66,84]$. The effect of variance in HR has shown both positive and negative impacts on BP in clinical data. In normal conditions, it has a positive relation but under baroreflex activity (the mechanism to regulate acute $\mathrm{BP}$ changes via controlling heart rate), $\mathrm{HR}$ is negatively correlated to $\mathrm{BP}[84,87,92]$. The other factor, arterial stiffness, has been assumed constant in algorithms based on those physical models (3) and (4). However, it influences the calibration frequency and can be estimated using ASI. The 
correlation factor using HR and the linear model (7) has been found to be around 0.79 for SBP and 0.814 for DBP [84], confirming its significance. It was also found that estimations based on the "maximum likelihood" and adaptive Kalman filter can reduce the number of calibration measurements required to estimate algorithm constants [88]. This model can be estimated by linear regression and offers ease in recalibration.

\subsection{Inverse Square Model}

Assuming arteries are rigid pipes, the work done by the travelling pressure wave can be expressed as a sum of its potential and kinetic energy where kinetic energy is dependent on PWV. The work done is equal to the change in BP with a fixed cross-sectional area and thus [73]:

$$
\mathrm{BP}=\frac{A}{\text { Time Delay }^{2}}+B
$$

where $A=\left(0.6 \times \frac{\text { height }}{\text { distance factor }}\right)^{2} \frac{\rho}{1.4}$ and $\rho$ is the average blood density.

Here, $B$ is estimated for individuals by using the "Time Delay" and cuff-based BP measurements. Fung et al. used PAT to estimate BP, assuming that the measurement obtained from peripheral sites like toes and fingers have insignificant delay due to PEP. However, for PPG at the ear, PAT should have been adjusted for PEP as the ear is closer to the heart, thus possessing a pressure wave similar to that in the central artery. For the estimation of A from the subject's height, an additional distance factor related to the locations of the PPG sensors was included. The distance factor was assumed to be 1, 0.5, and 1.6 for fingers, ears, and toes, respectively, in the study. The algorithm correlated to BP measured by cuff with a mean difference of $-0.0790 \mathrm{mmHg}$ and $11.32 \mathrm{mmHg}$ standard deviation. Furthermore, it was able to track both hypotension and hypertension. Wibmer et al. [85] modified the above relationship to account for the asymptotic behavior of $\mathrm{BP}$ as following:

$$
\mathrm{BP}=a+\left(\frac{b}{\text { Time Delay }-c}\right)^{2}
$$

In their study, PAT was obtained using PPG and a single-lead ECG signal and it had a high correlation factor with SBP while the correlation with DBP was similar as previously reported. Thus, the approach (9) adds reasonable asymptotic behavior which most models fail to achieve.

\subsection{Inverse Model}

The model represented by (9) also indicates the inverse relationship between BP and PTT and thus was used to obtain the subject-specific mathematical equation [54,93], where BP is calculated as follows

$$
\mathrm{BP}=\frac{a}{\text { Time Delay }}+b
$$

Additional parameters accounting for neural impact on BP were included to the inverse relationship given by (10). It has been reported that variability in both PTT and BP signals was coherent indicating that the neural system affects them simultaneously. When compensation for variability due to neural control was integrated with (10), the model gave results with higher accuracy for both DBP and SBP [69]. The study also incorporated the hydrostatic effects in the algorithm by measuring data for calibration in sitting and standing position. Model (10), if represented in terms of PWV, gives a direct relationship between PWV to BP [87]. In this case, the parameter L which is the distance between the sensor point and heart, was obtained using a subject-specific tape measure between the fossa jugularis and the sensor instead of relying on various ratios to subject's height. Marcinkevics et al. considered two PWV estimation methods, using $\mathrm{PAT}_{\mathrm{f}}$ and $\mathrm{PTT}_{\mathrm{f}}$, and obtained 
similar results [87]. Most experimental data suggest the inverse relationship between BP and PTT/PAT which is achieved by this model.

\subsection{Comparison between Models}

It was reported that those algorithms previously discussed yielded $\mathrm{R}^{2}$ values ranging from 0.02 to 0.97 as summarized in Table 1 . In order to apply a mathematical model, one needs to vary the BP over a considerable range to obtain the curve that can relate PTT/PAT closely to BP. Models under different conditions, generally exercising and medication, have been considered as summarized in Table 2. The same algorithm may result in different regression coefficients when using different BP perturbation techniques and calibration intervals, thus making comparisons difficult $[25,84]$. In order to give a better insight on this issue, in this work we elucidated four algorithms (6)-(8), and (10), using the Physionet online database as a source for the ECG, PPG and Arterial Blood Pressure (ABP). The database contains time-stamped nurse-verified physiological readings of patients in the intensive care unit at Boston's Beth Israel Deaconess Medical Center (BIDMC), beginning in 2001 and spanning seven years [94]. Individual demographic details, though vital in analyses, are unavailable as it can result in infringement of patient's privacy [95]. Two-leads ECG, finger PPG, and invasive ABP from one of the radial arteries were recorded at $125 \mathrm{~Hz}$ for varied lengths (weeks or more) using a bedside monitor. In this review, data which had at least five-minute long continuous recordings were considered for investigation. The ABP values listed were used for the calculation of SBP, DBP, and MAP. The four algorithms were evaluated using $\mathrm{PAT}_{\mathrm{f}}, \mathrm{PAT}_{\mathrm{m}}$, and $\mathrm{PAT}_{\mathrm{p}}$ for five adult patients (age $>15$ ) by using five different PATs and the average of five beat-to-beat ABP values as a reference. The unavailability of a second PPG signal restricted our evaluation to PAT. The Band-Altman plot for the expected measurement (BP values calculated from invasive ABP waveform) versus the calculated BP as well as $\mathrm{R}^{2}$ were used to analyze the four algorithms (Figure 4) [96-98]. The $x$-axis of the plots shows the average estimate of the algorithm that performed best and the $y$-axis represents the difference between the expected and measured values. Results indicated that the inclusion of $\mathrm{HR}$ in the BP algorithm for all three BP values (SBP, DBP, and MAP) gave higher regression coefficients between the measured and expected values with mean error and standard deviation (SD) within AAMI standards (Figure 4), and the use of $\mathrm{PAT}_{\mathrm{m}}$ and $\mathrm{PAT}_{\mathrm{p}}$ gave similar or better results than $\mathrm{PAT}_{\mathrm{f}}$. Using this algorithm, $92.3 \%$ MAP data is within the interval of $2 \cdot \mathrm{SD}$ and $85 \%$ of DBP estimates. In case of SBP, though using $\mathrm{PAT}_{\mathrm{p}}$ gave better $\mathrm{R}^{2}$, that of $\mathrm{PAT}_{\mathrm{m}}$ delivered a more-agreeable Bland-Altman plot with $96.1 \%$ data within the 2.SD interval (Figure 4). For both DBP and MAP, the mean of difference between the invasive BP and the one estimated using PAT and HR is small, indicating insignificant bias between the two methods. Average error and standard difference between the PAT based and the reference value is within AAMI standards for both MAP $(0 \pm 2.12)$ and DBP $(0 \pm 2.13)$ measurements. The SBP measurement has a slightly higher standard difference $(1.3 \pm 7.02)$, but it is still within the AAMI standard (Table 2). The larger disagreements between reference and measured SBP and DBP values for some of the data points is due to inclusion of data of hypertensive patients, as can be seen in Figure $4 \mathrm{a}$,c. Out of the five patients, two reported BP higher than $140 / 80 \mathrm{mmHg}$, resulting in higher disagreements in their case, which agrees with the study performed by Gesche and colleagues [89]. 
Table 2. Various BP perturbation techniques.

\begin{tabular}{ccc}
\hline Procedure & Description & Refs \\
\hline Physical Exercise & Graded Bicycle Test, Running, Sit-ups & {$[87,99]$} \\
\hline Posture & Sitting, standing and lying supine & {$[100]$} \\
\hline Valsalva Maneuver & Breathing against closed nose/mouth for 30 s & {$[101]$} \\
\hline Cold Pressure & $\begin{array}{c}\text { Placement of ice wrapped in wet cloth on subject's } \\
\text { forehead for 2 min. Hand in 4 }{ }^{\circ} \text { C water for 1 min }\end{array}$ & {$[102,103]$} \\
\hline Mental Arithmetic & $\begin{array}{c}\text { Counting backwards from 500 in intervals of 7, } \\
\text { Continuous addition of 3 digit numbers for 2 min }\end{array}$ & {$[104]$} \\
\hline Relaxation & Slow breathing / Meditative music & {$[105,106]$} \\
\hline Amyl Nitrate & Inhalation of vasodilator & {$[107]$} \\
\hline Anesthesia & Dental anesthesia & {$[84,108]$} \\
\hline Isometric Exercise & Raising legs/arms against pressure & {$[109]$} \\
\hline Sustained Handgrip & Clenching one's fist forcefully & {$[110,111]$} \\
\hline
\end{tabular}
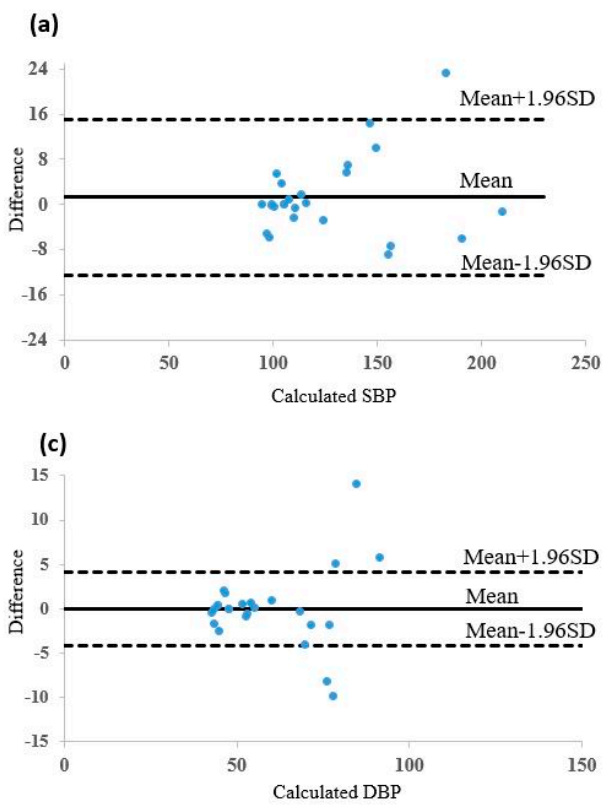

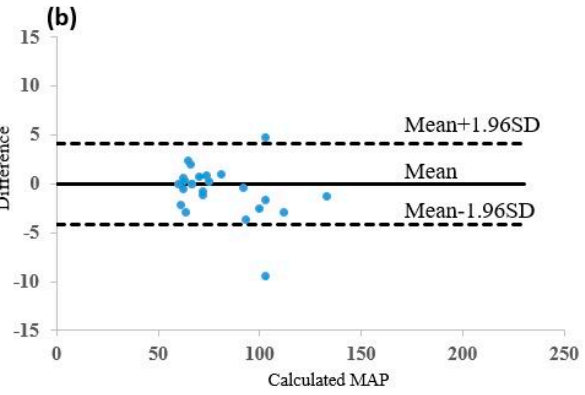

(d) Algorithm/Characteristic Point $\mathbf{P A T}_{\mathbf{f}} \mathbf{P A T}_{\mathrm{m}} \mathbf{P A T}_{\mathrm{p}}$ aln(PAT)+b $\quad 0.344630 .523$ $\begin{array}{lllll}\mathrm{a} / \mathrm{PAT}^{2}+\mathrm{b} & 0.30853 & 0.49768 & 0.3986\end{array}$ $\begin{array}{lllll}\mathrm{a} / \mathrm{PAT}+\mathrm{b} & 0.28161 & 0.50846 & 0.22552\end{array}$ $\begin{array}{lllll}a \mathrm{aPAT}+\mathrm{bHR}+\mathrm{c} & 0.68961 & 0.72158 & 0.77342\end{array}$

$\mathrm{aln}(\mathrm{PAT})+\mathrm{b} \quad 0.25548 \quad 0.40414 \quad 0.4008$ $\begin{array}{llll}\mathrm{a} / \mathrm{PAT}^{2}+\mathrm{b} & 0.23306 & 0.40174 & 0.3634\end{array}$ $\begin{array}{lllll}\mathrm{a} / \mathrm{PAT}+\mathrm{b} & 0.24618 & 0.41442 & 0.19722\end{array}$ aPAT+bHR+c $\quad 0.63623 \quad 0.67768 \quad 0.71179$

$\begin{array}{lllll}a \ln (\mathrm{PAT})+\mathrm{b} & 0.20242 & 0.35424 & 0.3729\end{array}$ a/PAT ${ }^{2+b} \quad 0.191210 .36786 \quad 0.34518$ $\begin{array}{lllll}\mathrm{a} / \mathrm{PAT}+\mathrm{b} & 0.19956 & 0.37378 & 0.1828\end{array}$ aPAT+bHR+c $\quad 0.59050 .63706 \quad 0.6575$

Figure 4. Bland-Altman plot between reference and measured (a) SBP using $a \mathrm{PATm}+b \mathrm{HR}+c$; (b) Mean arterial pressure (MAP) using $a$ PATp $+b \mathrm{HR}+c$; (c) Diastolic blood pressure (DBP) using $a \mathrm{PATp}+b \mathrm{HR}+c$; and (d) $\mathrm{R}^{2}$ obtained for different algorithms with significance level 0.05 .

Another study [112] provided a comparison between algorithms by Chen et al. and Poon et al. and they found that Chen's algorithm gave results within the standards for only a 4 min calibration interval and was unreliable in tracking large changes in BP, whereas Poon's algorithm required shorter calibration intervals to maintain a favorable accuracy. A recent study claimed that the inaccuracy of existing algorithms using PAT in tracking Low-Frequency (LF) variations in BP was one of the main reasons for inaccurate results $[90,113]$. In order to improve the accuracy, they introduced a factor termed "photoplethysmogram intensity ratio" (PIR), which could be determined by the ratio of the peak $\left(I_{p}\right)$ and the foot $\left(I_{f}\right)$ PPG values (Figure 3c). PIR was found mainly dependent on the arterial diameter and correlated with DBP $[90,113]$. Recently, machine learning-based techniques have been investigated [114] and promising results have been reported. In their work, various machine learning-based techniques were compared and they found that non-linear algorithms, like kernel machines or ensemble-learning methods as well as the AdaBoost model, gave better performances 
than linear approximations. Other techniques such as linear regression and decision tree were found not appropriate in predicting BP [114].

\section{Discussion}

Blood pressure is a complex parameter that has both physiological and neurological influences, and thus those need to be included to obtain a robust model. Heart rate (HR) represents the cardiac cycle and determines the heart's preload and the cardiac output (CO), which positively impact BP as the pressure on the arterial walls. HR is proportional to the volume of blood ejected $[115,116]$. HR and BP are also regulated by the autonomic nervous system which has been found to be inversely related, depending on the baroreflex activity [117]. HR is calculated from the RR interval in ECG signals and has been incorporated in several algorithms to estimate BP [84], demonstrating some improvement in accuracy. To consider the effect of the sympathetic system on BP, variability in PAT has been employed in the inverse model giving $\mathrm{R}^{2}$ of 0.96 when compared to those of cuff-based SBP tools [69]. The arterial stiffness affecting cushioning of arteries has been found to have implications on systolic hypertension $[53,118]$. Structural changes, such as those related to vascular aging and atherosclerosis, along with functional changes like increased BP or higher sympathetic activity, can impact the arterial stiffness [115]. Baek et al. described a method of estimating arterial stiffness index (ASI) as the time delay between the mid-point of the rising edge (incident) and characteristic point on the "dicrotic notch" (reflecting wave) of the PPG (Figure 3c) [84,115]. Shaltis et al. estimated the impact of hydrostatic pressure by varying the position of subject and measuring changes in PTT and BP, and through experimental data they concluded that gravity has a significant impact on BP [119]. These suggest that one may need to take more related parameters under consideration in order to establish an accurate and robust mathematical algorithm/model/relation to derive BP from the "Time Delay".

There are several other important issues that make time delay-based BP measurements challenging. To find the best fitting curve for PTT/PAT-based BP estimation, it is essential to vary $\mathrm{BP}$ over a wide range in order to have more points to construct the calibration curve. Significant variations in SBP can be achieved using some of the methods listed in Table 3, but it is difficult to vary DBP and MBP, restricting the development of accurate algorithms for these. Another issue arises due to the assumption of a tubular arterial system similar to central arteries which fails for the tapering peripheral branches. Peripheral branches have amplified pressure peaks due to wave reflection from arterial terminations, which need to be adjusted to estimate central artery pressure $[120,121]$.

Table 3. Mean error and standard deviation (in $\mathrm{mmHg}$ ) between measured and reference BP data.

\begin{tabular}{|c|c|c|c|c|}
\hline & Algorithm/Characteristic Point & $\mathrm{PAT}_{\mathrm{f}}$ & $\mathrm{PAT}_{\mathrm{m}}$ & $\operatorname{PAT}_{p}$ \\
\hline \multirow{4}{*}{ SBP } & $a \ln (\mathrm{PAT})+\mathrm{b}$ & $0.1 \pm 11$ & 8.9 & $0.3 \pm 11$ \\
\hline & $\mathrm{a} / \mathrm{PAT}^{2}+\mathrm{b}$ & $0.1 \pm 12$ & $0.1 \pm 12$ & $0.1 \pm 12$ \\
\hline & $\mathrm{a} / \mathrm{PAT}+\mathrm{b}$ & $0.1 \pm 13$ & $0.1 \pm 13$ & $0.1 \pm 13$ \\
\hline & $\mathrm{aPAT}+\mathrm{bHR}+\mathrm{c}$ & $0.1 \pm 14$ & $0.1 \pm 14$ & $0.1 \pm 14$ \\
\hline \multirow{4}{*}{ MAP } & $a \ln (\mathrm{PAT})+\mathrm{b}$ & $0.1 \pm 15$ & $0.1 \pm 15$ & $0.1 \pm 15$ \\
\hline & $\mathrm{a} / \mathrm{PAT}^{2}+\mathrm{b}$ & $0.1 \pm 16$ & $0.1 \pm 16$ & $0.1 \pm 16$ \\
\hline & $\mathrm{a} / \mathrm{PAT}+\mathrm{b}$ & $0.1 \pm 17$ & $0.1 \pm 17$ & $0.1 \pm 17$ \\
\hline & $\mathrm{aPAT}+\mathrm{bHR}+\mathrm{c}$ & $0.1 \pm 18$ & $0.1 \pm 18$ & $0.1 \pm 18$ \\
\hline \multirow{4}{*}{ DBP } & $a \ln (\mathrm{PAT})+\mathrm{b}$ & $0.1 \pm 19$ & $0.1 \pm 19$ & $0.1 \pm 19$ \\
\hline & $\mathrm{a} / \mathrm{PAT}^{2}+\mathrm{b}$ & $0.1 \pm 20$ & $0.1 \pm 20$ & $0.1 \pm 20$ \\
\hline & $\mathrm{a} / \mathrm{PAT}+\mathrm{b}$ & $0.1 \pm 21$ & $0.1 \pm 21$ & $0.1 \pm 21$ \\
\hline & $\mathrm{aPAT}+\mathrm{bHR}+\mathrm{c}$ & $0.1 \pm 22$ & $0.1 \pm 22$ & $0.1 \pm 22$ \\
\hline
\end{tabular}

Training algorithms require simultaneous recording of ECG/PPG and a gold standard tool for BP measurements. In many studies, this was carried out on different arms; however, BP is known to differ on both arms $[122,123]$ and hence the correlation between this BP and PTT/PAT had inherent 
errors. The inter-arm BP difference is usually not taken in account while doing the comparison, which can induce errors [124]. The PPG signal which has been widely used to estimate PTT and PAT is susceptible to motion artifacts and thus requires careful placement of sensors and signal processing techniques, such as the periodic moving average filter [125-127]. The PPG sensors need to be fixed accurately on the arterial position for BP derivation, as modifying the position would change the distance of propagation, and thus affect PWV and ultimately BP [128]. The contact force of PPG sensors at the site of placement has a considerable effect on the BP measurement and needs to be adjusted during calibration [129]. A study demonstrated that at positive transmural pressures, PTT increased with the applied contact force, reaching the maximum at the zero transmural pressure and remaining at a constant level at negative transmural pressures [130]. Further, the detection of various characteristic points on a PPG signal requires effective signal processing algorithms as it is susceptible to noise and motion [131-134]. Though several studies have attempted to calibrate BP for dynamic cases, most of them required subjects to stop exercising to estimate BP and therefore failed to provide real-time data [26]. Movements of arms and legs would affect the PPG signal, and it is thus advised to include hydrostatic effects on the PTT-BP mathematical model. Liu et al. demonstrated that the same BP can have different PAT, depending on whether the subject is at rest or exercising, possibly due to the differences in PEP [35]. Accelerometers can be used to determine different body positions (sleeping/walking/running, etc) and provide additional information in selecting appropriate algorithms to estimate BP $[17,130,135]$. Studies have shown that longer PTTs give better estimations than shorter ones, and this requires sensors to be placed far away from each other; consequently, compact devices would be difficult to achieve [136]. There is also a need to include heart rate variability (HRV), as it has been shown that HR can have both negative and positive effects on BP, and hence the same algorithm will fail to accurately predict BP if the variability is ignored [116].

It is extremely important to investigate the accuracy and appropriateness of any proposed models using measured data of a large pool of subjects, with both patients and regular populations, to reach any conclusion on a PTT/PAT-based device. Different standards, such as AAMI/ ISO, ESH-IP [137], and BHS [138], have been used to validate such a BP device, but insufficient data and varied statistical tools made it inadequate for comparisons. Those reported validations, at times, compromised on the number of subjects and observers required and thus failed to prove that the newly-developed devices were comparable with medical-grade systems. Since PTT/PAT-based devices are calibration dependent, there is a dire need to include the accuracy of the reference device. However, the gold standard for BP measurement in clinical settings, namely the arterial invasive line, is usually applied for inpatients in serious medication conditions only, while the widely-used cuff-based devices are not error free [139]. Therefore, the unavailability of high-precision clinical data has limited the investigations and validations of those PTT/PAT-based BP devices. Further, it is not feasible to acquire invasive BP data of a large number of various populations (including healthy people) for correlation in order to obtain statistical significance. Last but not least, it is also necessary to evaluate wearable continuous cuffless BP against continuous arterial (invasive/non-invasive) BP. Since, these PTT/PAT-based BP devices aim to provide continuous data, it would be more relevant to be validated/calibrated using continuous beat-to-beat $\mathrm{BP}$, rather than the $\mathrm{BP}$ averaged over a time, or discrete $\mathrm{BP}$ values.

In general, PTT/PAT-based BP devices have the capability of providing home-based monitoring in the form of a wearable linked with a smart device and thus mobile-heath (m-health) could be achieved with the connection to a cloud-based server. As a result, various approaches, such as the device with three chest sensors for PPG, ECG and ICG (impedance cardiogram) underneath a t-shirt, or ECG and PPG monitoring using circuitry on the toilet seats, beds and steering wheels, have been proposed and implemented $[19,20,128,140]$. In our group, the replacement of the three-electrode ECG configuration with a non-contact electrode (NCE) approach for ECG acquisition has been attempted. Different from regular contact-electrode ECG approaches which are dependent on the electrode-skin interface, NCE ECG could be obtained without any effects from the skin (sweat, hair, etc.), thus becoming of interest for off-the-clinic measurements. This method can further ease the signal acquisition as ECG data can 
be recorded using a single capacitive-coupling NCE in a specific point within the human body (i.e., wrist), thus holding promise for the realization of unobtrusive home-based BP monitoring wearable devices [38]. For instance, this approach can enable BP monitoring during sleeping or exercising without any hindrance to the users. Wireless communication via Bluetooth Low Energy (BLE) can be utilized to facilitate data collection and transfer locally among wearables for one user and globally with a cloud-based server, paving the way for real-time monitoring and diagnoses as well as distancedand self-care. However, the communication time among devices needs to be considered as it affects directly the calculation of the "Time Delay" [141].

\section{Conclusions}

With the present technology, it is possible to implement a PTT/PAT-based system that accurately predicts the trends of BP instead of measuring BP itself. Considerable fluctuations in this trend can be used as a warning signal for users to monitor their $\mathrm{BP}$ and continuous monitoring of this variation can be helpful in clinical environments, as most vital parameters in operational theatres are measured continuously except for BP. Therefore, the development of a cuffless BP monitoring system will provide novel solutions in various medical scenarios. The frequency of calibration as predicted by many studies was less than one hour, which is inappropriate as the artery stiffness and dimension could not change abruptly. This indicates that confounding factors need to be taken into account for PTT/PAT-based BP as many other factors apart from the "Time Delay" also have their contributions. From comparisons, we found that the inclusion of heart rate improved the efficiency of PAT-based BP measurement. Further, one may ask whether there is a need for continuous monitoring of $\mathrm{BP}$, and the answer may be not for healthy populations but crucial for CVD patients. Sleep apnea patients also require continuous BP monitoring; thus, a home-based system with connectivity to the caregiver online network would be of interest.

Acknowledgments: Manuja Sharma (M.S.) is supported by the scholarship under the Washington Research Foundation and the NSF CAREER Grant \#1652818 under Hung Cao (H.C.).

Author Contributions: Manuja Sharma, Victor Ho, Devon Griggs and Karinne Barbosa carried out experiments. Manuja Sharma processed and analyzed the data. Tadesse Ghirmai, Sandeep K. Krishnan, Tzung K. Hsiai and Jung-Chih Chiao gave advises and discussions. Manuja Sharma and Hung Cao initiated the manuscript. Hung Cao supervised and sponsored the entire work. All authors read the manuscript.

Conflicts of Interest: The authors declare no conflict of interest.

\section{References}

1. Laflamme, M.A.; Murry, C.E. Heart regeneration. Nature 2011, 473, 326-335. [CrossRef] [PubMed]

2. Cao, H.; Kang, B.J.; Lee, C.-A.; Shung, K.K.; Hsiai, T.K. Electrical and mechanical strategies to enable cardiac repair and regeneration. IEEE Rev. Biomed. Eng. 2015, 8, 114-124. [CrossRef] [PubMed]

3. Centers of Disease Control and Prevention. Vital signs: Awareness and treatment of uncontrolled hypertension among adults-United States, 2003-2010. Morb. Mortal. Wkly. Rep. 2012, 61, 703-709.

4. Ubolsakka-Jones, C.; Sangthong, B.; Aueyingsak, S.; Jones, D.A. Older Women with Controlled Isolated Systolic Hypertension: Exercise and Blood Pressure. Med. Sci. Sports Exerc. 2016, 48, 983-989. [CrossRef] [PubMed]

5. Moroz, L.A.; Simpson, L.L.; Rochelson, B. Management of severe hypertension in pregnancy. Semin. Perinatol. 2016, 40, 112-118. [CrossRef] [PubMed]

6. Booth, J. A short history of blood pressure measurement. Proc. R. Soc. Med. 1977, 70, 793-799. [PubMed]

7. Rocci, S.R. The technique of sphygmomanometry. Gazz. Med. Torino 1897, 10, 981-1017.

8. Korotkoff, N. On methods of studying blood pressure. Bull. Imp. Mil. Med. Acad. 1905, 11, 365-367.

9. Perloff, D.; Grim, C.; Flack, J.; Frohlich, E.D.; Hill, M.; McDonald, M.; Morgenstern, B.Z. Human blood pressure determination by sphygmomanometry. Circulation 1993, 88, 2460-2470. [CrossRef] [PubMed]

10. Rivarocci, S. Un nuovo sfigmomanometro. Gazz. Med. Torino 1896, 47, 981-1017. 
11. O'Brien, E.; Atkins, N. Accuracy of an oscillometric automatic blood pressure device: The Omron HEM403C. J. Hum. Hypertens. 1995, 9, 169-174.

12. O'Brien, E.; Waeber, B.; Parati, G.; Staessen, J. Blood pressure measuring devices: recommendations of the European Society of Hypertension. Br. Med. J. 2001, 322, 531-536. [CrossRef]

13. Leung, A.A.; Nerenberg, K.; Daskalopoulou, S.S.; McBrien, K.; Zarnke, K.B.; Dasgupta, K.; Cloutier, L.; Gelfer, M.; Lamarre-Cliché, M.; Milot, A.; et al. Hypertension Canada's 2016 Canadian Hypertension Education Program Guidelines for blood pressure measurement, diagnosis, assessment of risk, prevention, and treatment of hypertension. Can. J. Cardiol. 2016, 32, 569-588. [CrossRef] [PubMed]

14. JCS Joint Working Group. Guidelines for the clinical use of $24 \mathrm{~h}$ ambulatory blood pressure monitoring (ABPM) (JCS 2010). Circ. J. 2012, 76, 508-519.

15. Porter, K.B.; O’Brien, W.F.; Kiefert, V.; Knuppel, R.A. Flnapres: A Noninvasive Device To Monitor Blood Pressure. Obstet. Gynecol. 1991, 78, 430-433. [PubMed]

16. Kermode, J.; Davis, N.; Thompson, W. Comparison of the Finapres blood pressure monitor with intra-arterial manometry during induction of anaesthesia. Anaesth. Intensive Care 1989, 17, 470-475. [PubMed]

17. Thomas, S.S.; Nathan, V.; Zong, C.; Akinbola, E.; Aroul, A.L.P.; Philipose, L.; Soundarapandian, K.; Shi, X.; Jafari, R. BioWatch-A wrist watch based signal acquisition system for physiological signals including blood pressure. In Proceedings of the 2014 36th Annual International Conference of the IEEE Engineering in Medicine and Biology Society (EMBC), Chicago, IL, USA, 26-30 August 2014; pp. 2286-2289.

18. Kim, J.; Park, J.; Kim, K.; Chee, Y.; Lim, Y.; Park, K. Development of a nonintrusive blood pressure estimation system for computer users. Telemed. E-Health 2007, 13, 57-64. [CrossRef] [PubMed]

19. Kim, J.S.; Chee, Y.J.; Park, J.W.; Choi, J.W.; Park, K.S. A new approach for non-intrusive monitoring of blood pressure on a toilet seat. Physiol. Meas. 2006, 27, 203-211. [CrossRef] [PubMed]

20. Baek, H.J.; Lee, H.B.; Kim, J.S.; Choi, J.M.; Kim, K.K.; Park, K.S. Nonintrusive biological signal monitoring in a car to evaluate a driver's stress and health state. Telemed. E-Health 2009, 15, 182-189. [CrossRef] [PubMed]

21. Gu, W.; Poon, C.; Leung, H.; Sy, M.; Wong, M.; Zhang, Y. A novel method for the contactless and continuous measurement of arterial blood pressure on a sleeping bed. In Proceedings of the 2009 Annual International Conference of the IEEE Engineering in Medicine and Biology Society(EMBC), Minneapolis, MN, USA, 3-6 September 2009; pp. 6084-6086.

22. Nye, E. The effect of blood pressure alteration on the pulse wave velocity. Br. Heart J. 1964, 26, $261-265$. [CrossRef] [PubMed]

23. Gribbin, B.; Steptoe, A.; Sleight, P. Pulse wave velocity as a measure of blood pressure change. Psychophysiology 1976, 13, 86-90. [CrossRef] [PubMed]

24. Ahmad, S.; Chen, S.; Soueidan, K.; Batkin, I.; Bolic, M.; Dajani, H.; Groza, V. Electrocardiogram-assisted blood pressure estimation. IEEE Trans. Biomed. Eng. 2012, 59, 608-618. [CrossRef] [PubMed]

25. Choi, Y.; Zhang, Q.; Ko, S. Noninvasive cuffless blood pressure estimation using pulse transit time and Hilbert-Huang transform. Comput. Electr. Eng. 2013, 39, 103-111. [CrossRef]

26. Jeong, I.C.; Wood, J.; Finkelstein, J. Using individualized pulse transit time calibration to monitor blood pressure during exercise. Inf. Manag. Technol. Healthc. 2013, 190, 39-41.

27. Yoon, Y.; Cho, J.H.; Yoon, G. Non-constrained blood pressure monitoring using ECG and PPG for personal healthcare. J. Med. Syst. 2009, 33, 261-266. [CrossRef] [PubMed]

28. Špulák, D.; Čmejla, R.; Fabián, V. Parameters for mean blood pressure estimation based on electrocardiography and photoplethysmography. In Proceedings of the 2011 International Conference on Applied Electronics (AE), Pilsen, Czech Republic, 7-8 September 2011; pp. 1-4.

29. Lass, J.; Meigas, I.; Karai, D.; Kattai, R.; Kaik, J.; Rossmann, M. Continuous blood pressure monitoring during exercise using pulse wave transit time measurement. In Proceedings of the 26th Annual International Conference of the IEEE Engineering in Medicine and Biology Society (IEMBS 2004), San Francisco, CA, USA, 1-4 September 2004; pp. 2239-2242.

30. Poon, C.; Zhang, Y. Cuff-less and noninvasive measurements of arterial blood pressure by pulse transit time. In Proceedings of the 27th Annual International Conference of the Engineering in Medicine and Biology Society (EMBS 2005), Shanghai, China, 1-4 September 2005; pp. 5877-5880.

31. Lobodzinski, S.S.; Laks, M.M. New devices for very long-term ECG monitoring. Cardiol. J. 2012, 19, $210-214$. [CrossRef] [PubMed] 
32. Cattivelli, F.S.; Garudadri, H. Noninvasive cuffless estimation of blood pressure from pulse arrival time and heart rate with adaptive calibration. In Proceedings of the 2009 Sixth International Workshop on Wearable and Implantable Body Sensor Networks, Berkeley, CA, USA, 3-5 June 2009; pp. 114-119.

33. McCarthy, B.; O'Flynn, B.; Mathewson, A. An investigation of pulse transit time as a non-invasive blood pressure measurement method. J. Phys. Conf. Ser. 2011, 307, 012060. [CrossRef]

34. Singh, R.B.; Cornélissen, G.; Weydahl, A.; Schwartzkopff, O.; Katinas, G.; Otsuka, K.; Watanabe, Y.; Yano, S.; Mori, H.; Ichimaru, Y.; et al. Circadian heart rate and blood pressure variability considered for research and patient care. Int. J. Cardiol. 2003, 87, 9-28. [CrossRef]

35. Liu, Q.; Yan, B.P.; Yu, C.-M.; Zhang, Y.-T.; Poon, C.C. Attenuation of systolic blood pressure and pulse transit time hysteresis during exercise and recovery in cardiovascular patients. IEEE Trans. Biomed. Eng. 2014, 61, 346-352. [PubMed]

36. Wong, Y.; Zhang, Y. The effects of exercises on the relationship between pulse transit time and arterial blood pressure. In Proceedings of the 27th Annual International Conference of the Engineering in Medicine and Biology Society (EMBS 2005), Shanghai, China, 1-4 September 2005; pp. 5576-5578.

37. Wong, M.Y.-M.; Pickwell-MacPherson, E.; Zhang, Y.-T. The acute effects of running on blood pressure estimation using pulse transit time in normotensive subjects. Eur. J. Appl. Physiol. 2009, 107, 169-175. [CrossRef] [PubMed]

38. Griggs, D.; Sharma, M.; Naghibi, A.; Wallin, C.; Ho, V.; Barbosa, K.; Ghirmai, T.; Cao, H.; Krishnan, S.K. Design and development of continuous cuff-less blood pressure monitoring devices. In Proceedings of the 2016 IEEE Sensors, Orlando, FL, USA, 30 October-2 November 2016; pp. 1-3.

39. Goldberger, A.L.; Amaral, L.A.; Glass, L.; Hausdorff, J.M.; Ivanov, P.C.; Mark, R.G.; Mietus, J.E.; Moody, G.B.; Peng, C.-K.; Stanley, H.E. Physiobank, physiotoolkit, and physionet components of a new research resource for complex physiologic signals. Circulation 2000, 101, e215-e220. [CrossRef] [PubMed]

40. Fye, W.B. A history of the origin, evolution, and impact of electrocardiography. Am. J. Cardiol. 1994, 73, 937-949. [CrossRef]

41. Sundnes, J.; Lines, G.T.; Cai, X.; Nielsen, B.F.; Mardal, K.-A.; Tveito, A. Computing the Electrical Activity in the Heart; Springer Science \& Business Media: Berlin, Germany, 2007; Volume 1.

42. Braunwald, E.; Isselbacher, K.J.; Wilson, J.D.; Martin, J.B.; Kasper, D.; Hauser, S.L.; Longo, D.L. Harrison's Principles of Internal Medicine, 14th ed.; McGraw-Hill: New York, NY, USA, 1997.

43. Alastruey, J.; Parker, K.H.; Sherwin, S.J. Arterial pulse wave haemodynamics. In Proceedings of the 11th International Conference on Pressure Surges, Lisbon, Portugal, 24-26 October 2012; pp. 401-442.

44. Nichols, W.W.; O'Rourke, M.F.; Kenney, W.L. McDonald's Blood Flow in Arteries: Theoretical, Experimental and Clinical Principles, 3rd ed. J. Cardiopulm. Rehabil. Prev. 1991, 11, 407. [CrossRef]

45. Penaz, J. Photoelectric measurement of blood pressure, volume and flow in the finger. In Digest of the 10th International Conference on Medical and Biological Engineering; The Conference Committee: Dresden, Germany, 1973.

46. Wagenseil, J.E.; Mecham, R.P. Elastin in large artery stiffness and hypertension. J. Cardiovasc. Transl. Res. 2012, 5, 264-273. [CrossRef] [PubMed]

47. Geddes, L.A. Handbook of Blood Pressure Measurement; Springer Science \& Business Media: Berlin, Germany, 1991.

48. Peter, L.; Noury, N.; Cerny, M. A review of methods for non-invasive and continuous blood pressure monitoring: Pulse transit time method is promising? IRBM 2014, 35, 271-282. [CrossRef]

49. Hughes, D.; Babbs, C.; Geddes, L.; Bourland, J. Measurements of Young's modulus of elasticity of the canine aorta with ultrasound. Ultrason. Imaging 1979, 1, 356-367. [CrossRef] [PubMed]

50. Harkness, M.L.; Harkness, R.; McDonald, D. The collagen and elastin content of the arterial wall in the dog. Proc. R. Soc. Lond. B Biol. Sci. 1957, 146, 541-551. [CrossRef] [PubMed]

51. Burton, A.C. Relation of structure to function of the tissues of the wall of blood vessels. Physiol. Rev. 1954, 34, 619-642. [PubMed]

52. Ferrari, A.U.; Radaelli, A.; Centola, M. Invited review: aging and the cardiovascular system. J. Appl. Physiol. 2003, 95, 2591-2597. [CrossRef] [PubMed]

53. O'rourke, M.F.; Hashimoto, J. Mechanical factors in arterial aging: A clinical perspective. J. Am. Coll. Cardiol. 2007, 50, 1-13. [CrossRef] [PubMed] 
54. Mukkamala, R.; Hahn, J.-O.; Inan, O.T.; Mestha, L.K.; Kim, C.-S.; Töreyin, H.; Kyal, S. Toward ubiquitous blood pressure monitoring via pulse transit time: Theory and practice. IEEE Trans. Biomed. Eng. 2015, 62, 1879-1901. [CrossRef] [PubMed]

55. Cox, R.H. Regional variation of series elasticity in canine arterial smooth muscles. Am. J. Physiol. Heart Circ. Physiol. 1978, 234, H542-H551.

56. Moens, A.I. Die Pulskurve; EJ Brill: Leiden, The Netherlands, 1878.

57. Kanda, T.; Nakamura, E.; Moritani, T.; Yamori, Y. Arterial pulse wave velocity and risk factors for peripheral vascular disease. Eur. J. Appl. Physiol. 2000, 82, 1-7. [CrossRef] [PubMed]

58. Smith, R.P.; Argod, J.; Pépin, J.-L.; Lévy, P.A. Pulse transit time: an appraisal of potential clinical applications. Thorax 1999, 54, 452-457. [CrossRef] [PubMed]

59. Loukogeorgakis, S.; Dawson, R.; Phillips, N.; Martyn, C.N.; Greenwald, S.E. Validation of a device to measure arterial pulse wave velocity by a photoplethysmographic method. Physiol. Meas. 2002, 23, 581. [CrossRef] [PubMed]

60. Allen, J.; Murray, A. Age-related changes in peripheral pulse timing characteristics at the ears, fingers and toes. J. Hum. Hypertens. 2002, 16, 711-717. [CrossRef] [PubMed]

61. Chen, Y.; Wen, C.; Tao, G.; Bi, M.; Li, G. Continuous and noninvasive blood pressure measurement: A novel modeling methodology of the relationship between blood pressure and pulse wave velocity. Ann. Biomed. Eng. 2009, 37, 2222-2233. [CrossRef] [PubMed]

62. Nitzan, M.; Khanokh, B.; Slovik, Y. The difference in pulse transit time to the toe and finger measured by photoplethysmography. Physiol. Meas. 2001, 23, 85-93. [CrossRef]

63. Chen, Y.; Wen, C.; Tao, G.; Bi, M. Continuous and noninvasive measurement of systolic and diastolic blood pressure by one mathematical model with the same model parameters and two separate pulse wave velocities. Ann. Biomed. Eng. 2012, 40, 871-882. [CrossRef] [PubMed]

64. Allen, J. Photoplethysmography and its application in clinical physiological measurement. Physiol. Meas. 2007, 28, R1-R39. [CrossRef] [PubMed]

65. Chen, M.W.; Kobayashi, T.; Ichikawa, S.; Takeuchi, Y.; Togawa, T. Continuous estimation of systolic blood pressure using the pulse arrival time and intermittent calibration. Med. Biol. Eng. Comput. 2000, 38, 569-574. [CrossRef] [PubMed]

66. Zheng, Y.; Poon, C.C.; Zhang, Y.-T. Investigation of temporal relationship between cardiovascular variables for cuffless blood pressure estimation. In Proceedings of the 2012 IEEE-EMBS International Conference on Biomedical and Health Informatics (BHI), Hong Kong, China, 5-7 January 2012; pp. 644-646.

67. Ma, T.; Zhang, Y. A correlation study on the variabilities in pulse transit time, blood pressure, and heart rate recorded simultaneously from healthy subjects. In Proceedings of the 27th Annual International Conference of the Engineering in Medicine and Biology Society (EMBS 2005), Shanghai, China, 1-4 September 2005; pp. 996-999.

68. Schneider, J.A.; Davidson, D.M.; Winchester, M.A.; Taylor, C.B. The covariation of blood pressure and pulse transit time in hypertensive patients. Psychophysiology 1981, 18, 301-306.

69. Ma, H.T. A blood pressure monitoring method for stroke management. Biomed. Res. Int. 2014, $2014,571623$. [CrossRef] [PubMed]

70. García, M.T.G.; Acevedo, M.F.T.; Guzmán, M.R.; de Montaner, R.A.; Fernández, B.F.; del Río Camacho, G.; González-Mangado, N. Puede ser el tiempo de tránsito de pulso útil para detectar hipertensión arterial en pacientes remitidos a la unidad de sueño? Arch. Bronconeumol. 2014, 50, 278-284. [CrossRef] [PubMed]

71. Forouzanfar, M.; Ahmad, S.; Batkin, I.; Dajani, H.R.; Groza, V.Z.; Bolic, M. Model-based mean arterial pressure estimation using simultaneous electrocardiogram and oscillometric blood pressure measurements. IEEE Trans. Instrum. Meas. 2015, 64, 2443-2452. [CrossRef]

72. Li, Q.; Belz, G. Systolic time intervals in clinical pharmacology. Eur. J. Clin. Pharmacol. 1993, 44, 415-421. [CrossRef] [PubMed]

73. Fung, P.; Dumont, G.; Ries, C.; Mott, C.; Ansermino, M. Continuous noninvasive blood pressure measurement by pulse transit time. Conf. Proc. IEEE Eng. Med. Biol. Soc. 2004, 1, 738-741. [PubMed]

74. Ochiai, R.; Takeda, J.; Hosaka, H.; Sugo, Y.; Tanaka, R.; Soma, T. The relationship between modified pulse wave transit time and cardiovascular changes in isoflurane anesthetized dogs. J. Clin. Monit. Comput. 1999, 15, 493-501. [CrossRef] [PubMed] 
75. Solà, J.; Rimoldi, S.F.; Allemann, Y. Ambulatory Monitoring of the Cardiovascular System: The Role of Pulse Wave Velocity; INTECH Open Access Publisher: Rijeka, Croatia, 2010.

76. Naschitz, J.E.; Bezobchuk, S.; Mussafia-Priselac, R.; Sundick, S.; Dreyfuss, D.; Khorshidi, I.; Karidis, A.; Manor, H.; Nagar, M.; Peck, E.R.; et al. Pulse transit time by R-wave-gated infrared photoplethysmography: Review of the literature and personal experience. J. Clin. Monit. Comput. 2004, 18, 333-342. [CrossRef] [PubMed]

77. Payne, R.; Symeonides, C.; Webb, D.; Maxwell, S. Pulse transit time measured from the ECG: An unreliable marker of beat-to-beat blood pressure. J. Appl. Physiol. 2006, 100, 136-141. [CrossRef] [PubMed]

78. Young, C.C.; Mark, J.B.; White, W.; DeBree, A.; Vender, J.S.; Fleming, A. Clinical evaluation of continuous noninvasive blood pressure monitoring: accuracy and tracking capabilities. J. Clin. Monit. 1995, 11, 245-252. [CrossRef] [PubMed]

79. Zhang, G.; Gao, M.; Xu, D.; Olivier, N.B.; Mukkamala, R. Pulse arrival time is not an adequate surrogate for pulse transit time as a marker of blood pressure. J. Appl. Physiol. 2011, 111, 1681-1686. [CrossRef] [PubMed]

80. Noordergraaf, A. Circulatory System Dynamics; Elsevier: Amsterdam, The Netherlands, 2012; Volume 1.

81. Marie, G.V.; Lo, C.; van Jones, J.; Johnston, D.W. The relationship between arterial blood pressure and pulse transit time during dynamic and static exercise. Psychophysiology 1984, 21, 521-527. [CrossRef] [PubMed]

82. Proença, J.; Muehlsteff, J.; Aubert, X.; Carvalho, P. Is pulse transit time a good indicator of blood pressure changes during short physical exercise in a young population? In Proceedings of the 2010 Annual International Conference of the IEEE Engineering in Medicine and Biology (EMBC), Buenos Aires, Argentina, 31 August-4 September 2010; pp. 598-601.

83. Wong, M.Y.-M.; Poon, C.C.-Y.; Zhang, Y.-T. An evaluation of the cuffless blood pressure estimation based on pulse transit time technique: A half year study on normotensive subjects. Cardiovasc. Eng. 2009, 9, 32-38. [CrossRef] [PubMed]

84. Baek, H.J.; Kim, K.K.; Kim, J.S.; Lee, B.; Park, K.S. Enhancing the estimation of blood pressure using pulse arrival time and two confounding factors. Physiol. Meas. 2009, 31, 145-157. [CrossRef] [PubMed]

85. Wibmer, T.; Doering, K.; Kropf-Sanchen, C.; Rüdiger, S.; Blanta, I.; Stoiber, K.; Rottbauer, W.; Schumann, C. Pulse transit time and blood pressure during cardiopulmonary exercise tests. Physiol. Res. 2014, 63, 287-296. [PubMed]

86. Masè, M.; Mattei, W.; Cucino, R.; Faes, L.; Nollo, G. Feasibility of cuff-free measurement of systolic and diastolic arterial blood pressure. J. Electrocardiol. 2011, 44, 201-207. [CrossRef] [PubMed]

87. Marcinkevics, Z.; Greve, M.; Aivars, J.I.; Erts, R.; Zehtabi, A.H. Relationship between arterial pressure and pulse wave velocity using photoplethysmography during the post-exercise recovery period. Acta Univ. Latv. Biol. 2009, 753, 59-68.

88. Jadooei, A.; Zaderykhin, O.; Shulgin, V. Adaptive algorithm for continuous monitoring of blood pressure using a pulse transit time. In Proceedings of the 2013 IEEE XXXIII International Scientific Conference Electronics and Nanotechnology (ELNANO), Kiev, Ukraine, 16-19 April 2013; pp. 297-301.

89. Gesche, H.; Grosskurth, D.; Küchler, G.; Patzak, A. Continuous blood pressure measurement by using the pulse transit time: comparison to a cuff-based method. Eur. J. Appl. Physiol. 2012, 112, 309-315. [CrossRef] [PubMed]

90. Ding, X.-R.; Zhang, Y.-T.; Liu, J.; Dai, W.-X.; Tsang, H.K. Continuous cuffless blood pressure estimation using pulse transit time and photoplethysmogram intensity ratio. IEEE Trans. Biomed. Eng. 2016, 63, 964-972. [CrossRef] [PubMed]

91. Association for the Advancement of Medical Instrumentatio. American National Standard: Electronic or Automated Sphygmomanometers; AAMI: Washington, DC, USA, 1987.

92. Baldridge, B.R.; Burgess, D.E.; Zimmerman, E.E.; Carroll, J.J.; Sprinkle, A.G.; Speakman, R.O.; Li, S.-G.; Brown, D.R.; Taylor, R.F.; Dworkin, S.; et al. Heart rate-arterial blood pressure relationship in conscious rat before vs. after spinal cord transection. Am. J. Physiol. Regul. Integr. Comp. Physiol. 2002, 283, R748-R756. [CrossRef] [PubMed]

93. Griggs, M.S.D.; Naghibi, A.; Barbosa, K.; Ho, V.; Wallin, C.; Ghirmai, T.; Krishnan, S.; Cao, H. Design and Development of Continuous Cuff-Less Blood Pressure Monitoring Devices. In Proceedings of the 2016 IEEE Sensors, Orlando, FL, USA, 30 October-2 November 2016. 
94. Saeed, M.; Villarroel, M.; Reisner, A.T.; Clifford, G.; Lehman, L.-W.; Moody, G.; Heldt, T.; Kyaw, T.H.; Moody, B.; Mark, R.G. Multiparameter Intelligent Monitoring in Intensive Care II (MIMIC-II): A public-access intensive care unit database. Crit. Care Med. 2011, 39, 952-960. [CrossRef] [PubMed]

95. Tomson, J.; Lip, G.Y. Blood pressure demographics: nature or nurture...... genes or environment? BMC Med. 2005, 3, 3. [CrossRef] [PubMed]

96. Bland, J.M.; Altman, D.G. Measuring agreement in method comparison studies. Stat. Methods Med. Res. 1999, 8, 135-160. [CrossRef] [PubMed]

97. Bland, J.M.; Altman, D. Statistical methods for assessing agreement between two methods of clinical measurement. Lancet 1986, 327, 307-310. [CrossRef]

98. Bunce, C. Correlation, agreement, and Bland-Altman analysis: Statistical analysis of method comparison studies. Am. J. Ophthalmol. 2009, 148, 4-6. [CrossRef] [PubMed]

99. Fagard, R.H. Exercise characteristics and the blood pressure response to dynamic physical training. Med. Sci. Sports Exerc. 2001, 33, S484-S492. [CrossRef] [PubMed]

100. Longo, A.; Geiser, M.H.; Riva, C.E. Posture changes and subfoveal choroidal blood flow. Investig. Ophthalmol. Vis. Sci. 2004, 45, 546-551. [CrossRef]

101. Parati, G.; Casadei, R.; Groppelli, A.; di Rienzo, M.; Mancia, G. Comparison of finger and intra-arterial blood pressure monitoring at rest and during laboratory testing. Hypertension 1989, 13, 647-655. [CrossRef] [PubMed]

102. Ohlsson, O.; Henningsen, N. Blood pressure, cardiac output and systemic vascular resistance during rest, muscle work, cold pressure test and psychological stress. Acta Med. Scand. 1982, 212, 329-336. [CrossRef] [PubMed]

103. Peckerman, A.; Saab, P.G.; McCabe, P.M.; Skyler, J.S.; Winters, R.W.; Llabre, M.M.; Schneiderman, N. Blood pressure reactivity and perception of pain during the forehead cold pressor test. Psychophysiology 1991, 28, 485-495. [CrossRef] [PubMed]

104. Al'Absi, M.; Bongard, S.; Buchanan, T.; Pincomb, G.A.; Licinio, J.; Lovallo, W.R. Cardiovascular and neuroendocrine adjustment to public speaking and mental arithmetic stressors. Psychophysiology 1997, 34, 266-275. [CrossRef] [PubMed]

105. Agras, S.W.; Horne, M.; Taylor, B.C. Expectation and the blood-pressure-lowering effects of relaxation. Psychosom. Med. 1982, 44, 389-395. [CrossRef] [PubMed]

106. Davis, W.B.; Thaut, M.H. The influence of preferred relaxing music on measures of state anxiety, relaxation, and physiological responses. J. Music Ther. 1989, 26, 168-187. [CrossRef]

107. Steptoe, A.; Smulyan, H.; Gribbin, B. Pulse wave velocity and blood pressure change: Calibration and applications. Psychophysiology 1976, 13, 488-493. [CrossRef] [PubMed]

108. Matsumura, K.; Miura, K.; Takata, Y.; Kurokawa, H.; Kajiyama, M.; Abe, I.; Fujishima, M. Changes in blood pressure and heart rate variability during dental surgery. Am. J. Hypertens. 1998, 11, 1376-1380. [CrossRef]

109. Wiley, R.L.; Dunn, C.L.; Cox, R.H.; Hueppchen, N.A.; Scott, M.S. Isometric exercise training lowers resting blood pressure. Med. Sci. Sports Exerc. 1992, 24, 749-754. [CrossRef] [PubMed]

110. Petrofsky, J.S.; Lind, A.R. Aging, isometric strength and endurance, and cardiovascular responses to static effort. J. Appl. Physiol. 1975, 38, 91-95. [PubMed]

111. Petrofsky, J.S.; Burse, R.L.; Lind, A. Comparison of physiological responses of women and men to isometric exercise. J. Appl. Physiol. 1975, 38, 863-868. [PubMed]

112. McCarthy, B.; Vaughan, C.; O’Flynn, B.; Mathewson, A.; Mathúna, C.Ó. An examination of calibration intervals required for accurately tracking blood pressure using pulse transit time algorithms. J. Hum. Hypertens. 2013, 27, 744-750. [CrossRef] [PubMed]

113. Ding, X.-R.; Zhang, Y.-T. Photoplethysmogram intensity ratio: A potential indicator for improving the accuracy of PTT-based cuffless blood pressure estimation. In Proceedings of the 2015 37th Annual International Conference of the IEEE Engineering in Medicine and Biology Society (EMBC), Milan, Italy, 25-29 August 2015; pp. 398-401.

114. Kachuee, M.; Kiani, M.M.; Mohammadzade, H.; Shabany, M. Cuff-Less Blood Pressure Estimation Algorithms for Continuous Health-Care Monitoring. IEEE Trans. Biomed. Eng. 2017, 64, 859-869. [CrossRef] [PubMed]

115. Kim, J.S.; Kim, K.K.; Baek, H.J.; Park, K.S. Effect of confounding factors on blood pressure estimation using pulse arrival time. Physiol. Meas. 2008, 29, 615. [CrossRef] [PubMed] 
116. Drinnan, M.J.; Allen, J.; Murray, A. Relation between heart rate and pulse transit time during paced respiration. Physiol. Meas. 2001, 22, 425-432. [CrossRef] [PubMed]

117. di Rienzo, M.; Parati, G.; Radaelli, A.; Castiglioni, P. Baroreflex contribution to blood pressure and heart rate oscillations: Time scales, time-variant characteristics and nonlinearities. Philos. Trans. R. S. Lond. A Math. Phys. Eng. Sci. 2009, 367, 1301-1318. [CrossRef] [PubMed]

118. Nichols, W.; O’Rourke, M. McDonald's Blood Flow in Arteries, 4th ed.; Edward Arnold: London, UK, 1998.

119. Shaltis, P.; Reisner, A.; Asada, H. A hydrostatic pressure approach to cuffless blood pressure monitoring. In Proceedings of the 26th Annual International Conference of the IEEE Engineering in Medicine and Biology Society, San Francisco, CA, USA, 1-4 September 2004; pp. 2173-2176.

120. Gaddum, N.; Alastruey, J.; Beerbaum, P.; Chowienczyk, P.; Schaeffter, T. A technical assessment of pulse wave velocity algorithms applied to non-invasive arterial waveforms. Ann. Biomed. Eng. 2013, 41, 2617-2629. [CrossRef] [PubMed]

121. Gaballa, M.A.; Jacob, C.T.; Raya, T.E.; Liu, J.; Simon, B.; Goldman, S. Large Artery Remodeling During Aging Biaxial Passive and Active Stiffness. Hypertension 1998, 32, 437-443. [CrossRef] [PubMed]

122. Mayor, S. Doctors are urged to measure blood pressure in both arms. BMJ 2016, 353, i2577. [CrossRef] [PubMed]

123. Eşer, İ.; Khorshid, L.; Güneş, Ü.Y.; Demir, Y. The effect of different body positions on blood pressure. J. Clin. Nurs. 2007, 16, 137-140. [CrossRef] [PubMed]

124. Ng, K.-G. Review of measurement methods and clinical validation studies of noninvasive blood pressure monitors: Accuracy requirements and protocol considerations for devices that require patient-specific calibration by a secondary method or device before use. Blood Press. Monit. 2011, 16, 291-303. [CrossRef] [PubMed]

125. Han, H.; Kim, M.-J.; Kim, J. Development of real-time motion artifact reduction algorithm for a wearable photoplethysmography. In Proceedings of the 2007 29th Annual International Conference of the IEEE Engineering in Medicine and Biology Society, Lyon, France, 23-26 August 2007; pp. 1538-1541.

126. Poh, M.-Z.; Swenson, N.C.; Picard, R.W. Motion-tolerant magnetic earring sensor and wireless earpiece for wearable photoplethysmography. IEEE Trans. Inf. Technol. Biomed. 2010, 14, 786-794. [CrossRef] [PubMed]

127. Lee, H.; Lee, J.; Jung, W.; Lee, G.-K. The periodic moving average filter for removing motion artifacts from PPG signals. Int. J. Control Autom. Syst. 2007, 5, 701-706.

128. Solà, J.; Proença, M.; Ferrario, D.; Porchet, J.-A.; Falhi, A.; Grossenbacher, O.; Allemann, Y.; Rimoldi, S.F.; Sartori, C. Noninvasive and nonocclusive blood pressure estimation via a chest sensor. IEEE Trans. Biomed. Eng. 2013, 60, 3505-3513. [CrossRef] [PubMed]

129. Teng, X.; Zhang, Y. The effect of applied sensor contact force on pulse transit time. Physiol. Meas. 2006, 27, 675-684. [CrossRef] [PubMed]

130. Teng, X.-F.; Zhang, Y.-T. Theoretical study on the effect of sensor contact force on pulse transit time. IEEE Trans. Biomed. Eng. 2007, 54, 1490-1498. [CrossRef] [PubMed]

131. Yu, C.; Liu, Z.; McKenna, T.; Reisner, A.T.; Reifman, J. A method for automatic identification of reliable heart rates calculated from ECG and PPG waveforms. J. Am. Med. Inf. Associ. 2006, 13, 309-320. [CrossRef] [PubMed]

132. Foo, J.Y.A. Use of independent component analysis to reduce motion artifact in pulse transit time measurement. IEEE Signal Proc. Lett. 2008, 15, 124-126. [CrossRef]

133. Shin, H.S.; Lee, C.; Lee, M. Adaptive threshold method for the peak detection of photoplethysmographic waveform. Comput. Biol. Med. 2009, 39, 1145-1152. [CrossRef] [PubMed]

134. McDuff, D.; Gontarek, S.; Picard, R.W. Remote detection of photoplethysmographic systolic and diastolic peaks using a digital camera. IEEE Trans. Biomed. Eng. 2014, 61, 2948-2954. [CrossRef] [PubMed]

135. McCombie, D.B. Development of a Wearable Blood Pressure Monitor Using Adaptive Calibration of Peripheral Pulse Transit Time Measurements; Massachusetts Institute of Technology: Cambridge, MA, USA, 2008.

136. Douniama, C.; Sauter, C.; Couronne, R. Blood pressure tracking capabilities of pulse transit times in different arterial segments: A clinical evaluation. In Proceedings of the 2009 36th Annual Computers in Cardiology Conference (CinC), Park City, UT, USA, 13-16 September 2009; pp. 201-204. 
137. O’brien, E.; Pickering, T.; Asmar, R.; Myers, M.; Parati, G.; Staessen, J.; Mengden, T.; Imai, Y.; Waeber, B.; Palatini, P.; et al. Working Group on Blood Pressure Monitoring of the European Society of Hypertension International Protocol for validation of blood pressure measuring devices in adults. Blood Press. Monit. 2002, 7, 3-17. [CrossRef] [PubMed]

138. O'brien, E.; Petrie, J.; Little, W.; de Swiet, M.; Padfield, P.L.; Altma, D.G.; Bland, M.; Coats, A.; Atkins, N. Short report: An outline of the revised British Hypertension Society protocol for the evaluation of blood pressure measuring devices. J. Hypertens. 1993, 11, 677-679. [CrossRef] [PubMed]

139. Ribezzo, S.; Spina, E.; di Bartolomeo, S.; Sanson, G. Noninvasive techniques for blood pressure measurement are not a reliable alternative to direct measurement: A randomized crossover trial in ICU. Sci. World J. 2014, 2014, 363628. [CrossRef] [PubMed]

140. Zheng, Y.-L.; Ding, X.-R.; Poon, C.C.Y.; Lo, B.P.L.; Zhang, H.; Zhou, X.-L.; Yang, G.-Z.; Zhao, N.; Zhang, Y.T. Unobtrusive sensing and wearable devices for health informatics. IEEE Trans. Biomed. Eng. 2014, 61, 1538-1554. [CrossRef] [PubMed]

141. Chandrasekaran, V.; Dantu, R.; Jonnada, S.; Thiyagaraja, S.; Subbu, K.P. Cuffless differential blood pressure estimation using smart phones. IEEE Trans. Biomed. Eng. 2013, 60, 1080-1089. [CrossRef] [PubMed]

(C) 2017 by the authors. Licensee MDPI, Basel, Switzerland. This article is an open access article distributed under the terms and conditions of the Creative Commons Attribution (CC BY) license (http:/ / creativecommons.org/licenses/by/4.0/). 